\title{
SCIENTIFIC REPRTS \\ OPEN Erratum: Influence of different geographical factors on carbon sink functions in the Pearl River Delta
}

\section{Qian $X_{u^{1}}$, Yuxiang Dong ${ }^{1,2}$ \& Ren Yang ${ }^{1}$}

Scientific Reports 7:110; doi:10.1038/s41598-017-00158-z; Article published online 08 March 2017

In the original version of this Article, Yuxiang Dong was incorrectly listed as being affiliated with 'Guangdong Provincial Key Laboratory of Urbanization and Geo-simulation, Centre of Land Research, School of Geography and Planning, Sun Yat-sen University, Guangzhou, 510062, PR China. The correct affiliation is listed below:

'Guangdong Provincial Key Laboratory of Urbanization and Geo-simulation, Centre of Land Research, School of Geography and Planning, Sun Yat-sen University, Guangzhou, 510275, PR China’.

(c) (i) Open Access This article is licensed under a Creative Commons Attribution 4.0 International License, which permits use, sharing, adaptation, distribution and reproduction in any medium or format, as long as you give appropriate credit to the original author(s) and the source, provide a link to the Creative Commons license, and indicate if changes were made. The images or other third party material in this article are included in the article's Creative Commons license, unless indicated otherwise in a credit line to the material. If material is not included in the article's Creative Commons license and your intended use is not permitted by statutory regulation or exceeds the permitted use, you will need to obtain permission directly from the copyright holder. To view a copy of this license, visit http://creativecommons.org/licenses/by/4.0/.

(C) The Author(s) 2017
${ }^{1}$ Guangdong Provincial Key Laboratory of Urbanization and Geo-simulation, Centre of Land Research, School of Geography and Planning, Sun Yat-sen University, Guangzhou, 510275, PR China. ${ }^{2}$ Xinhua College of Sun Yat-sen University, Guangzhou, 510520, PR China. Correspondence and requests for materials should be addressed to Q.X. (email:xuxi3@mail2.sysu.edu.cn) 